OPEN ACCESS

Manuscript ID:

ECO-2021-09034019

Volume: 9

Issue: 3

Month: June

Year: 2021

P-ISSN: 2319-961X

E-ISSN: 2582-0192

Received: 10.04.2021

Accepted: 15.05.2021

Published: 01.06.2021

Citation:

Chithra, N. "A Study

on the Effectiveness of Competency Mapping in Enhancing Organizational Excellence with Special Reference to Salem Steel Plant in Salem District of Tamilnadu." Shanlax International Journal of Economics, vol. 9, no. 3, 2021, pp. 40-44.

DOI:

https://doi.org/10.34293/ economics.v9i3.4019

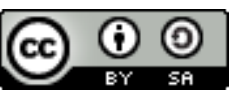

This work is licensed under a Creative Commons Attribution-ShareAlike 4.0 International License

\section{A Study on the Effectiveness of Competency Mapping in Enhancing Organizational Excellence with Special Reference to Salem Steel Plant in Salem District of Tamilnadu}

\author{
N. Chithra \\ Associate Professor and Research Advisor, PG and Research Department of Economics \\ Khadir Mohideen College, Adirampattinam, Thanjavur District, Tamil Nadu, India \\ D https://orcid.org/0000-0001-6541-1183
}

\begin{abstract}
One of the four conditions gives rise to the need for OD interventions. First, the organization has a problem; something is "broken" Corrective actions - interventions - are implemented to "fix" the problem. Second, the organization sees an unrealized opportunity; something it wants is beyond its reach. Enabling actions - interventions - are developed to seize the opportunity. Third, features of the organization are out of alignments; parts of the organization are working at crosspurposes. Alignment activities - interventions - are developed to get things back "in sync". Fourth, the vision guiding the organizations changes; yesterday's vision is no longer good enough. Actions to build the necessary structures, processes, and culture to support the new vision. Interventions are developed to make the new vision a reality.
\end{abstract}

Keywords: Organizational, Role efficacy, Steel, Mapping

\section{Introduction}

Development activities are usually described as interventions since they are considered and planned efforts to bring about change. An arrangement can be altered or changed by effecting dramatic changes in its structure, its technology, its people, or some organizations of these aspects. The people approach changing workers and management behavior by focusing on their skills, knowledge, attitudes and expectations. The structural approach means focusing on the span of management, delayering, altering lines of communication, combining departmental obligations, or a shift from one form of structure to another based on the difficulties of the moment. The technological procedure focuses on automation and computerization of office methods, work, and changes in research techniques, the engineering process as well as re-engineering.

\section{Statement of the Problem}

Many types of research are continuing in the said field in different dimensions, like how people and institutions function and how to get them to function better; the major thrust is given by Organizational Development Practitioners is on how to improve the functioning of individuals, teams, and the total organizations and another thrust is on to teach organization members how to continuously improve upon their functioning. The systematic approaches adopted in framing the Organizational Development strategy have given multiple benefits to the organizations. 
Enormous opportunities and potential exist for the Organizational Development movement in the future. Organizations throughout the world need the unique help to achieve effectiveness for which the development of organizations is essential. Paradoxically neither exist too many case studies on Indian organizations, which is perhaps need of hour due to rapid globalization of the Indian economy.

In the above backdrop, a study at this stage may focus on the current status of Organizational Development practices in Indian organizations, which will further enable to conduct of in-depth study across organizations within $\&$ across the industries.

\section{Objectives}

The following are the major objectives of the study:

- To find out the Role Efficacy of Participants in the Competency Mapping Intervention in Salem Steel Plant.

- To determine the outcomes of Customers Delight in Services Intervention by conducting a study on Rumination Analysis of Participants.

- To find out the effectiveness of Multi-skilling Intervention in Salem Steel Plant by studying Role Stress.

- To determine the effectiveness of Micro Planning Intervention conducted by Salem Steel Plant by studying Organizational Learning Diagnostics.

\section{Hypotheses}

The hypotheses framed during the study are as follows :

- Competency Mapping Intervention will have a positive impact in enhancing Role Efficacy.

- Customers' Delight Intervention in services will positively impact Dealing with Emotions (Rumination and Flow).

- Multi-skilling Intervention will have a positive impact in reducing Role Stress.

- Micro Planning Intervention will have a positive impact in enhancing Organisational Learning.

\section{Methods and Materials}

Database and Period of the Study

The study has employed both primary data and secondary data. The respondents collected the data by using the interview schedule method from February 2019 to February 2020.

\section{Selection of the Study Area \\ The Sample}

The study was restricted to Salem Steel Plant, Salem, Dist. Tamil Nadu sample for the present study was confined to Salem Steel Plant, Steel Authority of India Limited (SAIL), a "Maharatna Company," the leading steel-making company in India. It is a fully integrated iron and steel maker, producing both the primary and special steels for domestic construction, engineering, power, railway, automotive and defense industries and sale in export markets.

It is neither feasible nor desirable to conduct the study of the entire population. Moreover, an accurate assessment of Organizational Development intervention's effectiveness and outcomes can not be assessed from any single department or individual. For each Organizational Development intervention, people are involved at different levels in different departments. Therefore, sampling was done in which data were collected starting from the General Managers, Assistant General Managers to the level of Operating staff, who were directly a part of this intervention.

The study was conducted in 2 phases before the starting of the interventions. The data was collected (pre) from the participants and after the completion of the interventions, then again from the same participants, the information was collected (post) then the comparison and analysis were made to know the outcomes and effectiveness.

It is neither feasible nor desirable to conduct the study of the entire population. Moreover, an accurate assessment of Organizational Development programs can not be done by any single department or individual. Moreover, for each Organizational Development intervention, people are involved at a different level in different departments.

Therefore the 100 Employees in each intervention, who were directly a part of these interventions, were taken as samples and in Customers Delight in Services, 50 employees were taken as samples. Only 70 employees were there for these said interventions. 


\section{Sample Design}

The data was collected from permanent employees of Salem Steel Plant on a random basis.

- Top-level - 10 (which will consist of AGMs and Above)

- Middle Level - 20 (Supervisors up to the level of Managers)

- Lower Level - 70 (Technicians and Operators)

For each intervention, 10 Assistant General Managers (AGMs) were randomly selected from the shop floor where each intervention is used accordingly for four interventions, 31 Assistant General Managers were randomly selected.

Similarly, for each intervention, 20 middlelevel managers up to the level of Supervisors were randomly selected and accordingly, 65 middle-level managers were the sample respondents.

And 70 workforces from the level of technicians, operators and ministerial staff were randomly selected from the shop floors and the Departments where these said interventions were conducted. The sample respondent size in the category of technicians and operators is 254 .

However, in the case of Customers Delight - In Services intervention, the entire Telecommunication Department was covered and the total strength of the Department was 50 employees who comprised of 1- Assistant General Manager, 1- Manager, 4 Junior Executives and the rest 44 employees are Technicians and Operators. Accordingly, the break up of the sample size for each said intervention is as follows:

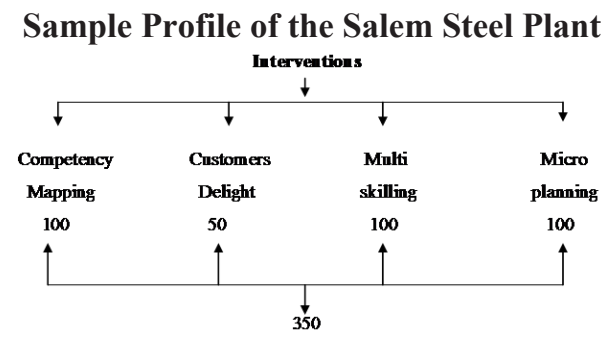

Table 1: Distribution of Sample among the Selected Respondents

\begin{tabular}{|l|c|c|c|c|}
\hline \multicolumn{1}{|c|}{ Interventions } & $\begin{array}{c}\text { AGMs upto the level of } \\
\text { General Managers }\end{array}$ & $\begin{array}{c}\text { Managers upto the } \\
\text { level of Supervisors }\end{array}$ & $\begin{array}{c}\text { Technicians and } \\
\text { Operators }\end{array}$ & Total \\
\hline Competency Mapping & 10 & 20 & 70 & 100 \\
\hline Customers Delight & 1 & 5 & 44 & 50 \\
\hline Multi-skilling & 10 & 20 & 70 & 100 \\
\hline Micro-planning & 10 & 20 & 70 & 100 \\
\hline Total Respondents & 31 & 65 & 254 & 350 \\
\hline
\end{tabular}

\section{Tools}

\section{For Competency Mapping Interventions}

Role Efficacy: Measured by a role efficacy scale, designed by UdaiPareek, a structured instrument consisting of 20 trials of statements. A respondent marks the one word in each practice that describes his role most accurately. It will be in the form of a questionnaire.

\section{For Multi Skilling Interventions}

Role Stress: This intervention was measured by an Organizational Role Stress Scale (ORS) designed by F. Burns, R. L. Gragg and Udai Pareek. ORS is a 5 point scale containing five items for each role stress and 50 statements.

\section{For Customers Delight in Services}

Rumination Analysis: It contains seven items; three items are pairs. The respondent is required to choose one item in each team. The others have statements in which the respondent was required to choose one item in each pair. This instrument is designed by $\mathrm{R}$. Roskins, J. K. Pillai and Muthaiah.

\section{For Micro Planning Intervention}

Organizational Learning Diagnostics of Salem

Steel Plant: This intervention was studied using a 5 point scale designed by M. Alexander, M. Sashkin and S. B. Parry. Organizational Learning Diagnostics has 23 items.

The questionnaire was administered separately for pre and post result evaluation of the program to assess the above-stated points. 


\section{Data Analysis and Results}

The objective of the present investigation was to study the effectiveness of Organizational Development interventions and how it has helped SALEM STEEL PLANT (SAIL), Salem to grow effectively, keeping pace with globalization, worldclass manufacturing practices and effective Human Resources Development.

This study was mainly focused on finding the effectiveness and outcomes a huge organization like Salem Steel Plant achieves by initiating and administering systematic organizational development interventions. The data was analyzed comparing the pre and post-status of the participants by using test and other statistical methods, which was relevant for the data.

\section{Collection of Data}

The 350 samples are selected by using the purposive random sampling technique.

Primary data are collected by schedule method from the informants by providing a pre-tested questionnaire. Data are collected in the study area for one calendar year.

The requisite secondary data are collected from the published materials and various related centers and organizations and the Salem Steel Plant.

\section{Findings}

- Competency Mapping Intervention will have a positive impact in enhancing Role Efficacy.

- From the obtained results, it is evident that the Role Efficacy Index in the pre-intervention stage was low $(\mathrm{M}=66.16)$ than the Role Efficacy Index in the post-intervention location $(\mathrm{M}=71.16)$. The $\mathrm{t}$-score was found to be significant $(\mathrm{t}=3.964$, $\mathrm{p}=0.027$ ), indicating that the Competency mapping Intervention had a substantial impact on enhancing Role Efficacy. Hence, the hypothesis stated as "Competency Mapping Intervention will positively impact Role Efficacy" is accepted.

- From the obtained results, it is evident that the Centrality score in the pre-intervention stage was low $(\mathrm{M}=2.57)$ than the Centrality score in the post-intervention set $(M=2.69)$. But the $\mathrm{t}$-score was found to be insignificant $(\mathrm{t}=1.421$, $\mathrm{p}=0.158$ ), indicating that the Competency mapping Intervention had a negligible impact on the Centrality aspect of Role Efficacy. Hence, the hypothesis stated as "Competency mapping Intervention will lead in enhancing Centrality" is rejected.

- From the obtained results, it is evident that the Integration score in the pre-intervention stage was low $(\mathrm{M}=1.43)$ than the Integration score in the post-intervention set $(M=1.86)$. But the $\mathrm{t}$-score was found to be insignificant $(\mathrm{t}=1.633$, $\mathrm{p}=0.106$ ), indicating that the Competency mapping Intervention had a negligible impact on the Integration aspect of Role Efficacy. Hence, the hypothesis stated as "Competency mapping Intervention will lead in enhancing Integration" is rejected.

- From the obtained results, it is evident that the Pro-activity score in the pre-intervention stage was low $(\mathrm{M}=1.34)$ than the Pro-activity score in the post-intervention set $(\mathrm{M}=1.67)$. But the $\mathrm{t}$-score was found to be insignificant $(\mathrm{t}=1.421$, $\mathrm{p}=0.159$ ), indicating that the Competency mapping Intervention had a negligible impact on the Proactivity aspect of Role Efficacy. Hence, the hypothesis stated as "Competency mapping Intervention will lead in enhancing Proactivity" is rejected.

- From the obtained results, it is evident that the Creativity score in the pre-intervention stage was low $(\mathrm{M}=2.26)$ than the Creativity score in the post-intervention stage $(\mathrm{M}=2.88)$. The $\mathrm{t}$-score was found to be significant $(\mathrm{t}=3.859$, $\mathrm{p}=0.026$ ), indicating that the Competency mapping Intervention had a substantial impact on enhancing the Creativity aspect of Role Efficacy. Hence, the hypothesis stated as "Competency mapping Intervention will lead in enhancing Creativity" is accepted.

- From the obtained results, it is evident that the Inter-Role Linkage score in the pre-intervention stage was low $(\mathrm{M}=1.69)$ than the Inter-Role Linkage score in the post-intervention set $(\mathrm{M}=1.91)$. But the $\mathrm{t}-$ the score was found to be insignificant $(\mathrm{t}=1.080, \mathrm{p}=0.283)$, indicating that the Competency mapping Intervention had a negligible impact on the Inter-Role Linkage aspect of Role Efficacy. Hence, the hypothesis 
stated as "Competency mapping Intervention will lead in enhancing Inter-Role Linkage" is rejected.

\section{Conclusion}

Competency Mapping Intervention will have a positive impact in enhancing Role Efficacy. It was also found that it will not have a major effect on Centrality, Integration, Pro-activity, Inter-Role Linkage, Helping Relationship, Super-ordination, Influence and Growth. It will enhance creativity and confrontation handling aspects of Role Efficacy.

Customers Delight in services intervention will have a positive impact on Dealing with Emotions (Rumination and Flow). It reduces Rumination and increases flow.

Micro Planning Intervention will have a positive impact in enhancing Organizational Learning. It enhanced innovation, implementation, stabilization, experimentation, mutuality, planning, systems and competency building.

Multi-skilling Intervention will have a positive impact in reducing Role Stress. This intervention has reduced inter-role distance, role stagnation, role expectation conflict, role erosion, role overload, role isolation, personal inadequacy, self role distance, role ambiguity, role inadequacy.

\section{References}

Awasthi, Shraddha. "Employee Development through Competency Mapping: A Way Ahead for Organizational Growth." International Journal in Management and Social Science, vol. 4, no. 6, 2016, pp. 260-270.

Broad, Mary L. "Managing the Organizational Learning Transfer System: A Model and
Case Study." Improving Learning Transfer in Organizations. Edited by Elwood F. Holton, and Timothy T. Baldwin, John Wiley, 2003, pp. 97-117.

Bruner, Jerome. The Process of Education. Vintage, 1960.

Cavaleri, Stephen A. "Leveraging Organizational Learning for Knowledge and Performance." The Learning Organization, vol. 11, no. 2, 2004, pp. 159-176.

Chawla, Anuradha, and E. Kevin Kelloway. "Predicting Openness and Commitment to Change." Leadership \& Organization Development Journal, vol. 25, no. 6, 2004, pp. 485-498.

Kansal, Jimmy, and Sandeep Singhal. "Development of a Competency Model for Enhancing the Organisational Effectiveness in a Knowledgebased Organisation." International Journal of Indian Culture and Business Management, vol. 16, no. 3, 2018.

Kreber, Carolin, and Patricia A. Cranton. "Exploring the Scholarship of Teaching." Journal of Higher Education, vol. 71, no. 4, 2000, pp. 476-495.

Nordhaug, Odd, and Kjell Grongaug. "Competences as Resources in Firms." International Journal of Human Resources Management, vol. 5, no. 1, 1994, pp. 89-106.

Sessa, Valerie I., and Manuel London. Continuous Learning in Organizations: Individual, Group, and Organizational Perspectives. Lawrence Erlbaum Associates, 2006.

Young, M. Clarifying Competency and Competence. Henley Working Paper, 2002.

\section{Author Details}

Dr. N. Chithra, Associate Professor and Research Advisor, PG and Research Department of Economics, Khadir Mohideen College, Adirampattinam, Thanjavur District, Tamil Nadu, India,

Email ID: chithrasubarnaa@gmail.com 